\title{
Experimental Study on Bearing Capacity of Underpinning Joints under the Influence of the Different Roller Arrangement
}

\author{
Si Daolin ${ }^{1, \text { a, * }}$ \\ ${ }^{1}$ School of Management Engineering, Jinan Engineering Vocational Technical College, Jinan \\ 250200, China \\ asd1198532@163.com
}

Keywords: structural engineering; underpinning joints; roller arrangement; failure forms.

\begin{abstract}
Underpinning is a key link in the building moving technology, and the different roller arrangement of underpinning beam directly impacts on the stability and the security of moving process of building. Through the experiment of the wrap-underpinning joints under frame columns, the relationship is studied between the fracture morphology of the underpinning joints and the different roller arrangement of underpinning beam, and also the influence is determined by the different roller arrangement of underpinning beam on the force mechanism and failure forms. The results show that the crack load was influenced hardly by the roller arrangement, neither inside arrangement nor full arrangement, but the ultimate bearing capacity was increased approximately by 30\% and 1 times separately. When the roller inside arrangement, the failure form of underpinning joint is flexural failure of the underpinning beam, and full arrangement, failure mode of bonding interface between underpinning-beam and column was relative slippage.
\end{abstract}

\section{Introduction}

Nowadays, Building Monolithic Moving Technology has been widely used in urban redevelopment, urban demolition, road widening and ancient architecture protection [1]. However, the study on the Building Monolithic Moving Technology are obviously lagging behind the engineering practice. There is no unified formula for the size of the traction force, the design method of the track beam and the upper beam is lack of normative basis, and the underpinning structure is not yet reasonable [2].

Underpinning is a key link in the Building Monolithic Moving Technology. It is the critical technique deciding the success of a moving key technologies and it directly impact on the stability and the security of moving process of building[3].

Through the orthogonal experiment of scale model for the wrap-underpinning joints under frame columns, the influence of the different roller arrangement of underpinning beam to the fracture morphology and bearing capacity was mainly studied in this article.In addition, the basis of practical application were tabled for Building Monolithic Moving Technology in the future. 


\section{Experimental Design}

\subsection{Specimen design}

This test is a statical loading test. The scale model of the frame column underpinning joint specimens of 4 groups (2 pieces in each group) were designed by orthogonal design method, considered the Influence factors of the underpinning structure reinforcement, the strength of the concrete and so on [4]. The reinforcing bars for underpinning structure is shown in Figure 1 and the parameters of specimens is shown in Table 1. The columns and underpinning beams are poured in batches with different grades of concrete strength, and all of the junction surface were chiseled. A specimens of each group are arranged from the cantilever root of the walking beam, the JD1-B and JD3-B are full arranged with rollers, and the JD2-B and JD4-B rollers are moved to the edge of the column, which is specifically arranged as shown in Figure 2. Among them, a is the side length of the column, $b$ is the width of the underpinning beam, $l$ is the cantilever length of the underpinning beam, $h$ is the depth of the underpinning beam height, $L$ is the total length of the specimen, and $B$ is the total width of the specimen.
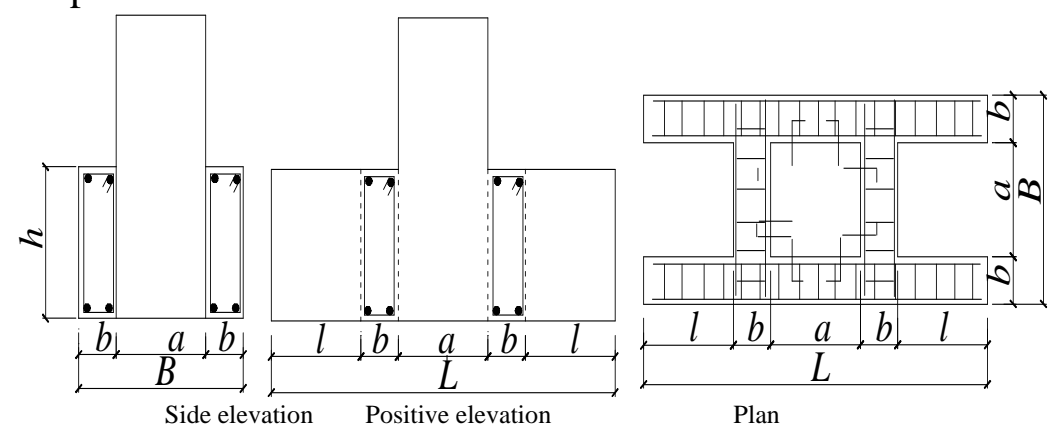

Fig. 1 Reinforcing bars for underpinning structure

Table 1 parameters of specimens

\begin{tabular}{|c|c|c|c|c|c|c|c|c|c|}
\hline Specimen & $\begin{array}{l}\text { Concrete } \\
\text { strength }\end{array}$ & $a / \mathrm{mm}$ & $b / \mathrm{mm}$ & $h / \mathrm{mm}$ & $\mathrm{l} / \mathrm{mm}$ & $L / \mathrm{mm}$ & $\mathrm{B} / \mathrm{mm}$ & stirrup & $\begin{array}{l}\text { longitudinal } \\
\text { reinforcement }\end{array}$ \\
\hline 1 & C20(C25) & 300 & 125 & 200 & 300 & 1150 & 550 & $\square 6 @ 180$ & $2 \square 14$ \\
\hline 2 & C20(C25) & 300 & 125 & 300 & 300 & 1150 & 550 & $\square 8 @ 150$ & $2 \square 12$ \\
\hline 3 & C30(C35) & 300 & 125 & 200 & 300 & 1150 & 550 & $\square 8 @ 100$ & $2 \square 12$ \\
\hline 4 & C30(C35) & 300 & 125 & 300 & 300 & 1150 & 550 & $\square 6 @ 125$ & $3 \square 10$ \\
\hline & \begin{tabular}{|l|l|} 
& \\
$\mid$ & \\
& \\
\end{tabular} & 1 & & $\begin{array}{lll} & 1 \\
1 & 1 \\
1 & 1\end{array}$ & $\begin{array}{l}1 \\
1\end{array}$ & & 1 & \begin{tabular}{l|l} 
& 1 \\
1 & 1 \\
& \\
\end{tabular} & \\
\hline
\end{tabular}
(a) the roller normal arrangement
(b) the roller inside arrangement
(c) the roller full arrangement

Fig. 2 roller layout

\subsection{Load measurement}

Hydraulic jacks are used to load the specimen in this test, as shown in Figure 3. The measurement contents of the underpinning joints test include load value, concrete strain, steel strain, roller strain, and crack development of walking beam and connecting beam [5]. 


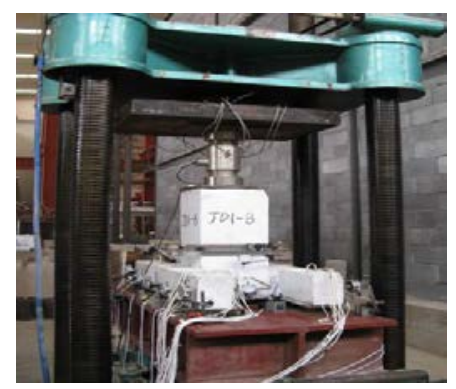

Fig. 3 Load and displacement measurement

\section{Test Process and Phenomenon}

\subsection{Test process and phenomenon of the roller normal arrangement}

Take sample JD2-A as an example to illustrate: The first crack occurs in the span of the walking beam when the specimen JD2-A is loaded to $150 \mathrm{kN}$; the load increased to $400 \mathrm{kN}$, the crack widens gradually, and the bending crack develops toward the middle of the span. At this time, the longitudinal reinforcement tensile stress at the cantilever root increases rapidly, but the stress change of the longitudinal reinforcement is not obvious in the middle of the span. The load increased to $500 \mathrm{kN}$, the crack width changes obviously, the tensile stress of the longitudinal reinforcement of the walking beam increases rapidly, and the oblique cracks on both sides are gradually penetrated. When loading to $700 \mathrm{kN}$, a large shear arched crack is formed on the JD2-A walking beam with the maximum crack width of $3.5 \mathrm{~mm}$, and the specimen is damaged by the bending shear failure, as shown in Figure 4.

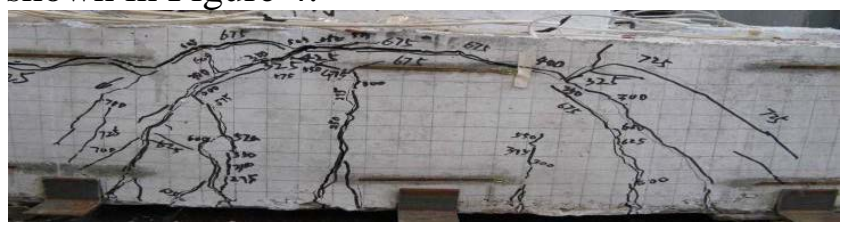

Fig. 4 Bending-shear failure

\subsection{Test process and phenomenon of the roller inside arrangement}

Take sample JD2-B as an example to illustrate: The specimen JD2-B cracking load is also 150kN, but the cracking position is at the cantilever root of the walking beam; the load increased to $300 \mathrm{kN}$, there is an inflection point in the strain curve of the longitudinal reinforcement in the span of the walking beam, and the relative displacement of the old and new concrete joint is beginning to change. The load increased to $600 \mathrm{kN}$, the tensile stress of the longitudinal reinforcement in the span of the walking beam increases rapidly and approaches yield. The load increased to $950 \mathrm{kN}$, the longitudinal steel bars of the walking beams yield and the specimen is damaged by the bending failure, as shown in Figure 5.

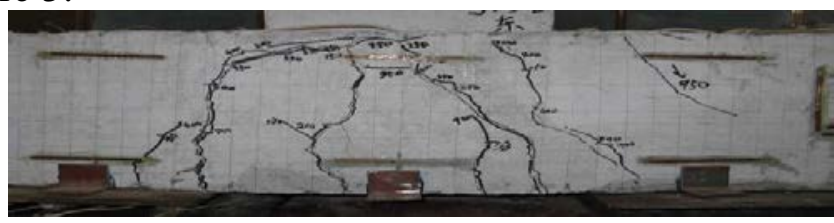

Fig. 5 Bending failure 


\subsection{Test process and phenomenon of the roller full arrangement}

Take sample JD3-B as an example to illustrate: The specimen JD3-B cracking load is 50kN and the cracking position is at the cantilever root of the walking beam. The load increased to $700 \mathrm{kN}$, the relative slip of the junction surface between the new and old concrete beam and column suddenly increases. The load increased to $800 \mathrm{kN}$, horizontal cracks occur along the four sides of underpinning beams, and the concrete of the column foot and column edges is crushed. The load increased to $900 \mathrm{kN}$, the column suddenly sinks and the load cannot be stabilized, resulting in the punching shear failure of the joint surface, as shown in Figure 6.

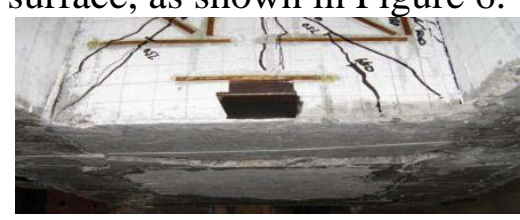

Fig. 6 Punching failure of joint section

\section{Test Results and Analysis}

In order to analyze the influence of roller layout on the bearing capacity of underpinning joints, table 2 lists the crack load and failure load of each specimen.

Table 2 Crack load and failure load of each specimen

\begin{tabular}{|c|c|c|c|c|}
\hline specimen & Roller arrangement & crack load $/ k N$ & failure load $/ k N$ & failure forms \\
\hline JD2-A & $\begin{array}{c}\text { normal } \\
\text { arrangement }\end{array}$ & 150 & 700 & Bending-shear failure \\
\hline JD2-B & inside arrangement & 150 & 950 & Bending failure \\
\hline JD4-A & $\begin{array}{c}\text { normal } \\
\text { arrangement }\end{array}$ & 100 & 600 & Bending-shear failure \\
\hline JD4-B & inside arrangement & 100 & 750 & Bending failure \\
\hline JD1-A & $\begin{array}{c}\text { normal } \\
\text { arrangement }\end{array}$ & 100 & 425 & Bending-shear failure \\
\hline JD1-B & full arrangement & 90 & - & Undamaged \\
\hline JD3-A & $\begin{array}{c}\text { normal } \\
\text { arrangement }\end{array}$ & 60 & 450 & Bending failure \\
\hline JD3-B & full arrangement & 50 & 900 & Punching failure \\
\hline
\end{tabular}

It can be seen from table 2 that when the roller is moved inside and the roller is placed normally, the crack load is the same and the first crack appears on the walking beam, but the failure load is increased by $25 \%$ to $36 \%$. When the final damage occurs, the roller inside arrangement specimens is due to the bending yield of the longitudinal reinforcement in the walking beam, which leads to the increase of the joint surface slip. So, their failure forms are all subjected to bending failure.

Compared with the roller normal arrangement, the roller full arrangement has little effect on the crack load of the specimen, and the first crack appears on the walking beam also, but the failure load is doubled. Under the condition of the roller full arrangement, the roller can resist the bending deformation of the walking beam, can effectively resist the bending moment, and limit the increase of the deflection of the walking beam. In the process of this destruction, the joint surface is damaged seriously, and its failure type is the punching shear failure of the joint surface.

\section{Conclusion}

It can be concluded from the experiment that the roller inside arrangement and the roller full 
arrangement have little effect on the cracking load of the specimen. The failure load of the roller inside arrangement is increased by $25 \%$ to $36 \%$, and the failure load of the roller full arrangement is doubled. Therefore, increasing the contact area between the underpinning beam and the roller can improve the bearing capacity of the component. So, in the practical engineering application, it is necessary to ensure that the rollers are uniformly distributed under the underpinning beam, so as to reduce the deformation of the underpinning beam and improve the bearing capacity of the underpinning node.

\section{References}

[1] Zhang Xin. Advances of building moving technolog[J]. Journal OF Shandong University of Architecture and Engineering. 2005, 20(5): 75-81.

[2] Zhang Xin, Jia Liudong, Wei Huanwei, Xia Fengmin. Technique of building moving and rectification[M]. Beijing: China Water Power Press, 2008.

[3] Jia Liudong, Xia Fengmin, Zhang Xin, Zhang Aishe. Relocation moving design and in-situ monitoring for a fifteen-story building[J]. Journal of Building Structures, 2009, 30(6): 134-141.

[4] Yue Qingxia, Zhang Xin, Jia Liudong, Wang Heng.Research on shearing capacity of underpinning beams in frame structure moving based on strut-and-tie model[J]. Journal of Building Structures, 2012, 33(10): 110-115.

[5] Tan Tianle. Experimental research on mechanical behavior of column underpinning joint bonding interface between beam and column for structure moving [D]. Jinan: Shandong Jianzhu University, 2010. 